\title{
Treatment of Middle Cerebral Artery Aneurysms with Flow- Diverter Stents: A Systematic Review and Meta-Analysis
}

\author{
(D)F. Cagnazzo, (DD. Mantilla, (DP.-H. Lefevre, DC. Dargazanli, (D) G. Gascou, and (D) V. Costalat
}

\begin{abstract}
BACKGROUND: The safety and efficacy of flow-diversion treatment of MCA aneurysms have not been well-established.
\end{abstract}

PURPOSE: Our aim was to evaluate angiographic and clinical outcomes after flow diversions for MCA aneurysms.

DATA SOURCES: A systematic search of PubMed, MEDLINE, and Embase was performed for studies published from 2008 to May 2017.

STUDY SELECTION: According to Preferred Reporting Items for Systematic Reviews and Meta-Analyses guidelines, we selected studies with $>5$ patients describing angiographic and clinical outcomes after flow-diversion treatment of MCA aneurysms.

DATA ANALYSIS: Random-effects meta-analysis was used to pool the following outcomes: aneurysm occlusion rate, procedure-related complications, rupture rate of treated aneurysms, and occlusion of the jailed branches.

DATA SYNTHESIS: Twelve studies evaluating 244 MCA aneurysms were included in this meta-analysis. Complete/near-complete occlusion was obtained in $78.7 \%(95 \% \mathrm{Cl}, 67.8 \%-89.7 \%)$ of aneurysms. The rupture rate of treated aneurysms during follow-up was $0.4 \%$ per aneurysm-year. The rate of treatment-related complications was $20.7 \%(95 \% \mathrm{Cl}, 14 \%-27.5 \%)$, and approximately $10 \%$ of complications were permanent. The mortality rate was close to $2 \%$. Nearly $10 \%(95 \% \mathrm{Cl}, 4.7 \%-15.5 \%)$ of jailed arteries were occluded during follow-up, whereas $26 \%(95 \% \mathrm{Cl}, 14.4 \%-37.6 \%)$ had slow flow. Rates of symptoms related to occlusion and slow flow were close to $5 \%$.

LIMITATIONS: Small and retrospective series could affect the strength of the reported results.

CONCLUSIONS: Given the not negligible rate of treatment-related complications, flow diversion for MCA aneurysms should be considered an alternative treatment when traditional treatment methods are not feasible. However, when performed in this select treatment group, high rates of aneurysm occlusion and protection against re-rupture can be achieved.

ABBREVIATION: PRISMA = Preferred Reporting Items for Systematic Reviews and Meta-Analyses

$\mathbf{F}$ ow-diverter stents have become a feasible and effective treatment for most intracranial aneurysms, and their indications are constantly extended, including distal aneurysm locations. ${ }^{1-3}$ Commonly, middle cerebral artery aneurysms present with a particularly complex anatomy because of the frequency of wide-neck configurations with incorporating MCA branches. Endovascular treatment of MCA aneurysms can be technically more challeng-

Received June 16, 2017; accepted after revision July 18

From the Neuroradiology Department, University Hospital Güi-de-Chauliac Centre Hospitalier Universitaire de Montpellier, Montpellier, France.

Please address correspondence to Federico Cagnazzo, MD, Neuroradiology Department, CHU Gui De Chauliac, 80 Ave Augustin Fliche, 34000 Montpellier, France; e-mail: f.cagnazzo86@gmail.com

$\equiv$ Indicates article with supplemental on-line tables.

Indicates article with supplemental on-line photos.

http://dx.doi.org/10.3174/ajnr.A5388 ing, and in many institutions, surgical treatment is considered the first option because of the high rate of long-term occlusion with low surgical morbidity. ${ }^{4}$ However, with the improvement of angiographic images, increased operator experience, and the use of more complex techniques, an increasing number of MCA aneurysms are treated with endovascular techniques. ${ }^{1}$ Recently, flow diversion has been used as an alternative technique for complex wide-neck MCA aneurysms, incorporating $\geq 1$ side branch or in cases of previous endovascular or surgical failure. ${ }^{5-14}$ However, the role of flow diversion in this location is controversial, and the efficacy and safety of this technique remain unclear. We performed a systematic review and meta-analysis of all published series examining flow diversions for the treatment of MCA aneurysms with the aim of clarifying the following: 1) aneurysm occlusion rate, 2) treatment-related complications and clinical outcome, and 3) the fate of the MCA side branch covered with the device. 


\section{MATERIALS AND METHODS Literature Search}

A comprehensive literature search of PubMed, Ovid MEDLINE, and Ovid Embase was conducted for studies published from 2008 to May 2017. The Preferred Reporting Items for Systematic Reviews and Meta-Analyses (PRISMA) guidelines were followed. ${ }^{15}$ The key words "middle cerebral artery," "flow-diverter," "flow diversion," "anterior circulation," "aneurysms," "pipeline," and "endovascular" were used in both "AND" and "OR" combinations. The detailed search strategy is reported in On-line Table 1. The inclusion criteria were the following: 1) studies reporting series of patients with MCA aneurysms treated with flow diverters. Exclusion criteria were the following: 1) studies with $<5$ patients, 2) review articles, 3) studies published in languages other than English, 4) in vitro studies, and 5) animal studies. In cases of overlapping patient populations, only the series with the largest number of patients or the most detailed data were included. Two reviewers independently selected the included studies, and a third author solved discrepancies.

\section{Data Collection}

From each study, we extracted the following information: 1) characteristics and number of MCA aneurysms, 2) aneurysm occlusion rate and related factors, 3 ) incidence of aneurysm rupture after treatment, 4) treatment-related complications, and 5) angiographic outcome of covered arteries. The rate of aneurysm occlusion was dichotomized into 2 groups: complete/near-complete occlusion and incomplete occlusion. Accordingly, the influence of 6 parameters (age, mean aneurysm size, type of stent used, first treatment versus retreatment, type of first treatment, and anatomic location of MCA aneurysms) on the occlusion rates was analyzed. MCA aneurysms were divided into 3 categories: saccular, fusiform, and blister. $\mathrm{Pa}-$ tients with blister aneurysms $(n=3)$ were considered for only the incidence of arterial occlusion after flow-diverter deployment. On the basis of the location, MCA aneurysms were dichotomized into "prebifurcation" (M1 and early cortical branches) and bifurcation aneurysms (M1-M2 bifurcation and M2 bifurcation branches). ${ }^{16}$ Complications related to the treatment were summarized in 4 categories: ischemic/thromboembolic, hemorrhagic, iatrogenic (dissection or perforation), and perianeurysmal inflammation. The rate of occlusion and diminished flow of covered branches was analyzed from only studies that specifically reported the angiographic outcome of covered arteries. Finally, good outcome was defined as a modified Rankin Scale score of $0-2$ or a Glasgow Outcome Score of 4-5. In cases in which the mRS and Glasgow Outcome Score were not reported, good neurologic outcome was determined if the study used terms such as "no morbidity," "good recovery," or "no symptoms."

\section{Outcomes}

The primary objectives were to define the following: 1) the rate of MCA aneurysm occlusion, 2) the incidence of treatmentrelated complications, and 3) the rate of MCA branch occlusion covered with flow diverters and the incidence of related symptoms.

\section{Quality Scoring}

The Newcastle-Ottawa Scale ${ }^{17}$ was used to assess the quality of the included studies (On-line Table 2) evaluating the following: patient selection criteria, comparability of the study groups, and exposure assessment. "High-quality" studies were defined on the basis of the following: 1) the presence of a predefined study protocol, 2) defined inclusion and exclusion criteria, 3) adequate clinical and radiologic follow-up, and 4) detailed information about treatment-related outcomes. Accordingly, a star rating of $0-9$ was allocated to each study. The quality assessment was performed by 2 authors independently, and a third author solved discrepancies. Studies receiving $\geq 6$ stars were considered high-quality.

\section{Statistical Analysis}

We estimated, from each cohort, the cumulative prevalence and $95 \%$ confidence interval for each outcome. Rates of each outcome were pooled in meta-analyses across studies by using the randomeffects model. ${ }^{18}$ We chose this model a priori because it incorporates both within-study and between-studies variances. This is recommended when data are heterogeneous. Heterogeneity of the treatment effect across studies was evaluated with the $\mathrm{I}^{2}$ statistic, in which an $\mathrm{I}^{2}$ value of $>50 \%$ suggests substantial heterogeneity. ${ }^{19}$ We also extracted a $2 \times 2$ table for each studied outcome for interaction testing and calculated $P$ values for the comparisons between the previously mentioned clinical and anatomic characteristics. Meta-regression was not used in this study. Statistical analysis was performed by using the software program OpenMeta[Analyst] (http://www.cebm.brown.edu/openmeta/).

\section{RESULTS}

\section{Literature Review}

The search strategy is summarized in On-line Table 1, and studies included in our meta-analysis are summarized in Table. The search flow diagram is shown in On-line Fig 1.

Twelve studies and 244 MCA aneurysms treated with flowdiverter stents were included in our review.

\section{Quality of Studies}

Overall, 8 studies were rated high quality. Seven of the high-quality studies specifically analyzed flow-diversion treatment of MCA aneurysms (On-line Table 2). All the high-quality articles reported detailed information about aneurysm occlusion rates, treatment-related complications, flow modifications of covered arteries, and adequate length of follow-up.

\section{Patient Population and Aneurysm Characteristics}

The mean age of patients was 54.5 years (range, 3-76 years), and the male/female ratio was 0.6 (On-line Table 3). Overall, $88.1 \%$ (95\% CI, 83.4\%-91.6\%) of treated MCA aneurysms were unruptured, whereas $11.9 \%$ (95\% CI, 8.3\%-16.5\%) (median, 1\%; IQR, $0.4 \%-2.5 \%$ ) were previously ruptured and were treated with coils or clipping in the acute phase. The median time of flow-diversion treatment after rupture was 8.5 months (IQR, 3.2-36 months). Saccular and fusiform aneurysms were $81.1 \%$ (95\% CI, 75.7\%$85.5 \%)$ and $17.6 \%$ (95\% CI, 13.3\%-22.9\%), respectively. Blister aneurysms represented $1.3 \%$ ( $95 \% \mathrm{CI}, 0.2 \%-3.7 \%$ ) of the lesions. 


\begin{tabular}{|c|c|c|c|c|c|}
\hline Variables & Raw Numbers ${ }^{a}$ & No. of Articles & $95 \% \mathrm{Cl}$ & $1^{2}$ & $P$ Value \\
\hline \multicolumn{6}{|l|}{ MCA aneurysm occlusion after flow diversion } \\
\hline Overall rate of complete/near-complete occlusion & $137 / 171=78.7 \%$ & 10 & $67.8-89.7$ & 76.24 & $<.001$ \\
\hline \multicolumn{6}{|l|}{ Factors related to aneurysm occlusion } \\
\hline Mean age (yr) & & & & & .262 \\
\hline Complete/near-complete occlusion & $53.6 \mathrm{yr}$ & 4 & $47.3-59.8$ & $75 \%$ & \\
\hline Incomplete occlusion & $61.3 \mathrm{yr}$ & & $48.9-73.5$ & $95 \%$ & \\
\hline Mean size & & & & & .614 \\
\hline Complete/near-complete occlusion & $7 \mathrm{~mm}$ & 6 & $3.6-10.3$ & $83.6 \%$ & \\
\hline Incomplete occlusion & $5.5 \mathrm{~mm}$ & & $0.8-10.1$ & $99 \%$ & \\
\hline Complete/near-complete occlusion & & & & & .38 \\
\hline Retreatment & $64 \%$ & 5 & 33.9-93.4 & $75.2 \%$ & \\
\hline vs & vs & & & & \\
\hline First treatment & $73 \%$ & & $63-83.5$ & $0 \%$ & \\
\hline Complete/near-complete occlusion & & & & & .307 \\
\hline Prebifurcation (Ml-early cortical branches) & $88.1 \%$ & 11 & $79.6-96.7$ & $0 \%$ & \\
\hline vs & vs & & & & \\
\hline Bifurcation aneurysms & $77.7 \%$ & & $64.5-89.5$ & $74.92 \%$ & \\
\hline \multicolumn{6}{|l|}{ Complications related to treatment and outcome } \\
\hline Overall rate of treatment-related complications & $46 / 213=20.7 \%$ & 11 & $14-27.5$ & $34.03 \%$ & .126 \\
\hline Transient or asymptomatic & $11.3 \%$ & & $7.6-16.2$ & & \\
\hline vs & vs & 11 & $6.8-15.2$ & & \\
\hline Permanent & $10.3 \%$ & & & & \\
\hline \multicolumn{6}{|l|}{ Type of complications } \\
\hline Ischemic/thromboembolic & $16.3 \%$ & 11 & $10.1-22.6$ & $36.65 \%$ & .106 \\
\hline Hemorrhagic & $2 \%$ & & $0.2-3.9$ & $0 \%$ & .958 \\
\hline latrogenic (dissection/perforation) & $1.8 \%$ & & $0 \%-1.3 .5 \%$ & $0 \%$ & .973 \\
\hline Perianeurysmal inflammation & $2.6 \%$ & & $0.5-4.7$ & $0 \%$ & .997 \\
\hline Complications related to discontinuation of antiplatelet therapy & $4 / 46=8.7 \%$ & 11 & $2.9-20.8$ & & \\
\hline Aneurysm rupture after treatment & $1 / 214=0.47 \%$ & 12 & $0.1-2.8$ & & \\
\hline Overall rate of good outcome & $125 / 135=92.7 \%$ & 7 & $86.4-99.1$ & $42.08 \%$ & .11 \\
\hline Mortality rate & $4 / 213=2 \%$ & 11 & $0.2-3.9 \%$ & $0 \%$ & .929 \\
\hline
\end{tabular}

Note:- vs indicates versus.

${ }^{a}$ Results of meta-analysis.

Overall, 76.3\% (95\% CI, 70.5\%-81.1\%) of aneurysms were located at the main bifurcation point (M1-M2) or distally (M2), whereas prebifurcation aneurysms (M1-early cortical branches) were $23.7 \%$ (95\% CI, 18.8\%-29.5\%). Mean aneurysm size was 8.2 $\mathrm{mm}$ (range, $2-20 \mathrm{~mm}$ ).

\section{Treatment Characteristics}

The most common device used was the Pipeline Embolization Device (PED; Covidien, Irvine, California) (71\%; 95\% CI, $64.1 \%-75.3 \%$ ), followed by the Silk flow diverter (Balt Extrusion, Montmorency, France) device (11.4\%; 95\% CI, 80.3\%-15.9\%) (On-line Table 3). Most of the aneurysms were treated with 1 device (number of stents/aneurysm $=1.14$ ). The flow-diversion technique was used as a first treatment technique in $75.5 \%$ of patients (95\% CI, 69.4\%-80.6\%).

Digital subtraction angiography was the principal diagnostic technique. In about $90 \%$ of the reported patients, DSA was performed during the early and long-term radiologic follow-up. In approximately $10 \%$ of patients, MRA or CTA was performed during the long-term radiologic follow-up.

\section{Angiographic Outcomes and Treatment-Related Complications}

The overall rate of complete/near-complete occlusion during follow-up was $78.7 \%$ (95\% CI, 67.8\%-89.7\%) with a 12-month median duration (IQR, 8.1-16 months) of angiographic follow-up (Table and On-line Fig 2A). Differences in occlusion rates were not statistically significant among groups of age, mean aneurysm size, first treatment versus retreatment, type of first treatment (endovascular versus surgical), type of device used (PED versus other stents), and MCA aneurysm location ("prebifurcation" versus bifurcation aneurysms $)(P>.05)$.

The rate of treatment-related complications was $20.7 \%$ (95\% CI, 14\%-27.5\%) (On-line Fig 2B), and approximately 10\% of complications were permanent. Ischemic/thromboembolic events were the most common type of complications (16.3\%), followed by perianeurysmal inflammation $(2.6 \%)$, hemorrhage (2\%), and dissection/perforation (1.8\%). The mortality rate after treatment was $2 \%(95 \% \mathrm{CI}, 0.2 \%-3.9 \%)$. The rate of complications related to premature discontinuation of the antiplatelet therapy was $8.7 \%$ (95\% CI, 2.9\%-20.8\%). During follow-up, the incidence of aneurysm rupture after treatment was $0.47 \%(95 \%$ CI, $0.1 \%-2.8 \%$ ), with a rupture rate of $0.4 \%$ per aneurysm-year. The overall rate of good neurologic outcome after treatment was $92.7 \%$ (95\% CI, 86.4\%-99.1\%) with a 12-month median duration (IQR, 7.5-10.5 months) of clinical follow-up. Considering the group of patients with a history of aneurysm rupture, the rate of good neurologic outcome was close to $87 \%$ (95\% CI, $60.7 \%-98 \%)$.

\section{Outcome of Covered MCA Side Branches}

Overall, 174 MCA side branches jailed with flow diverters were available for the analysis (On-line Table 4). The global rate of 
occlusion of covered arteries was 10.1\% (95\% CI, 4.7\%-15.5\%), whereas $26 \%$ (95\% CI, $14.4 \%-37.6 \%$ ) of cases showed diminished flow (On-line Fig 3). The mean number of devices across the ostium of the arteries was similar between arteries with occlusion and those with normal flow (1.07 versus 1$)$. The incidence of symptoms (ischemic stroke in the MCA territory) related to MCA branch occlusion and diminished flow was $2.7 \%$ (95\% CI, 0.4\%$5 \%$ ) and 2.6\% (95\% CI, 0.1\%-5.1\%), respectively (On-line Fig 4).

\section{Study Heterogeneity}

Significant heterogeneity was noted in the analysis of aneurysm occlusion rates after treatment. In addition, significant heterogeneity was reported in the analysis of diminished flow of covered branches.

\section{DISCUSSION}

Our meta-analysis stressed several important findings related to the flow-diversion treatment of MCA aneurysms. The overall rate of complete/near-complete occlusion was approximately $80 \%$. The rupture rate after treatment was low $(0.4 \%$ per aneurysmyear), demonstrating that the aneurysms were successfully secured after flow diversion. Most of the lesions were small and located at the main bifurcation point (M1-M2). The overall complication rate of $20 \%$ is not negligible, resulting in permanent neurologic deficits in approximately $10 \%$ of patients and treatment-related mortality in about $2 \%$. Most interesting, most of the unfavorable outcomes were related to ischemic or thromboembolic complications. Our study also found a remarkable incidence of occlusion (10\%) and diminished flow (25\%) of covered MCA branches, resulting in neurologic symptoms in about $5 \%$ of patients. These findings are important and showed that though flow diversion is an effective treatment, MCA aneurysms amenable to flow diversion should be carefully selected, due to the not negligible rates of treatment-related morbidity.

\section{Angiographic Outcomes of MCA Aneurysms after Flow Diversion}

Flow-diverter stents have become a suitable tool for complex, wide-neck, and anatomically challenging intracranial aneurysms. However, while large and prospective studies demonstrated the safety and effectiveness of flow diversion for ICA aneurysms, the literature is contradictory about the treatment of distal locations, such as MCA aneurysms. Although surgery still represents an effective treatment for MCA aneurysms, difficult-to-treat lesions with conventional endovascular or surgical approaches have increased the use of flow diversion in this location. Overall, previous series have reported a rate of complete/near-complete occlusion between $60 \%$ and $90 \%$ after flow-diversion treatment of MCA aneurysms. ${ }^{5-9,12-14,20}$ The paucity of large and prospective studies, the heterogeneity of the reported populations, and the relatively short follow-up periods can explain this variation. Our study, the largest to date, demonstrated that the overall rate of complete/near-complete occlusion is roughly $80 \%$ during a mean follow-up of 14 months. This result is comparable with the angiographic occlusion rates of ICA aneurysms after flow diversion. In a recent prospective study of nearly 200 aneurysms, Kallmes et $\mathrm{al}^{3}$ reported 75\% complete occlusion after Pipeline treatment. Simi- larly, in a large meta-analysis of nearly 1700 aneurysms, the complete occlusion rate was close to $76 \% .^{21}$

Aneurysms of the MCA often arose from the main division point (bifurcation aneurysms), whereas in nearly $20 \%$ of cases, they originated from an early cortical branch (temporal or frontal). ${ }^{16}$ Early cortical branch aneurysms have a close relation with perforators, whereas bifurcation aneurysms are close to or incorporate M2 branches, influencing the outcomes after surgical or endovascular treatment. ${ }^{12}$ Very few articles analyzed differences in endovascular treatments for different MCA aneurysm locations, and it is possible that in the literature, most of the early cortical branch aneurysms are referred to as bifurcation aneurysms. Topcuoglu et al, ${ }^{12}$ in a series of 29 MCA aneurysms treated with flow diversion, reported better angiographic results among lesions located at the prebifurcation point (M1 or early bifurcations), compared with MCA bifurcation aneurysms (85\% versus $60 \%$ of complete/near-complete occlusion). In addition, unsatisfactory aneurysm occlusion was significantly related to the patency of the arterial branches originating from it. Our study demonstrated that the prevalence of complete/near-complete occlusion was slightly higher for aneurysms located at the prebifurcation point, compared with bifurcation (M1-M2) or more distal aneurysms (M2), though the result did not reach statistical significance $(88 \%$ versus $77 \%, P=.3$ ). In addition, there were no differences in occlusion rates between aneurysms treated with the PED and other types of stents. Similarly, we found that occlusion rates among younger patients and the first-treatment group versus the retreatment group appeared slightly higher, but without statistical relevance. However, among retreatment groups, complete/near-complete occlusion after flow diversion was slightly higher for aneurysms previously treated with coiling or stentassisted coiling (89\%), compared with aneurysms previously treated with clipping (63\%), though the results were not statistically significant. Finally, the rupture rate after treatment of $0.4 \%$ per aneurysm-year showed that flow diversion gives an effective protection against aneurysm rupture. ${ }^{22}$

\section{Treatment-Related Complications}

In general, treatment-related morbidity after flow diversion is reported to be between $4 \%$ and $10 \% .^{3,23-25}$ Our meta-analysis provides more representative data on complication rates after flowdiverter treatment of MCA aneurysms. This location should be considered separately in terms of technical complexity and treatment-related outcomes. The overall incidence of complications close to $20 \%$ is not negligible. Most important, permanent complications were approximately $10 \%$, whereas the mortality rate after treatment was $2 \%$. However, the literature is still contradictory about flow diversion among MCA aneurysms, and despite some authors concluding that it seems a reasonable treatment, ${ }^{9,13}$ others reported that it is not a suitable solution for aneurysms in this location. ${ }^{8}$ Our study showed that most of the reported complications were related to ischemic or thromboembolic events (16\%). Compared with the general rate of ischemic complications related to flow diversion, MCA location appears associated with a higher risk of ischemic injury. In the IntrePED ${ }^{24}$ study, as well as in other large studies, ${ }^{21,26}$ the rate of acute ischemic stroke was 
close to $5 \%$, with most of the reported events occurring in the early postoperative period.

A number of important mechanisms can explain the incidence of postoperative infarction after flow-diversion treatment of MCA aneurysms, such as perioperative catheter-related thromboemboli, acute/subacute in-stent thrombosis, or particle emboli from the devices. ${ }^{27-29}$ In our study, nearly $9 \%$ of ischemic complications were associated with discontinuation of the antiplatelet therapy, which showed the close relationship between ischemic injury and antiplatelet function. ${ }^{30}$ Another important factor is the risk of perforating injury due to coverage of lenticulostriate arteries. Multiple overlapping devices ${ }^{29}$ or undersized stents with more condensed pores and higher mesh density ${ }^{31}$ can increase the risk of perforator occlusion. In a series of 17 anterior circulation aneurysms, 12 of them arising from the MCA, Gawlitza et $\mathrm{al}^{20}$ reported $40 \%$ ischemic events after coverage of perforator arteries with flow-diverter stents, though most were asymptomatic. Despite the high rate of complications, most of the MCA aneurysms treated with flow diverters were anatomically complex, increasing the risk of procedure-related complications. Accordingly, when more complex endovascular techniques are required, such as $\mathrm{X}$ and Y-stent placement or stent-assisted coiling, a large series and meta-analysis reported permanent complications between $4 \%$ and $10 \% .^{32,33}$

\section{Angiographic Outcome of Covered Side Branches}

Placement of flow-diverter stents at the bifurcation points behind the circle of Willis has a potential risk of arterial occlusion. Due to the mechanical properties of the stent, the pressure gradient across the jailed branch is reduced, and if the "flow competition" from the collateral supply is well-represented, the artery can be occluded. ${ }^{34}$ MCA bifurcation presents an anatomic configuration without direct collateral arterial connection, and the anastomotic circulation is only with corticopial branches. Our study found $10 \%$ occlusion of covered MCA branches. In addition, remodelling of jailed arteries, such as slow flow or arterial narrowing, was present in about $25 \%$ of cases. Among large series of flow diverters covering ICA branches, the rates of side branch occlusion are close to $18 \%$ for the posterior communicating artery ${ }^{35-37}$ and $5 \%$ for the ophthalmic and anterior choroidal arteries, with rates of related symptoms close to $1 \% .^{35,38-42}$ In our study, approximately $5 \%$ of patients with occluded or narrowed MCA branches were symptomatic due to transient ischemic events.

\section{Strengths and Limitations}

Our study has several limitations. First, $\mathrm{I}^{2}$ results were above $50 \%$ for many of the estimates, suggesting substantial heterogeneity among the analyzed outcomes. The articles were often small, retrospective, and single-institution series, affecting the strength of the reported results. Factors related to procedural complications were not assessed, due to the scant data available. Details of the management of antiplatelet therapy were variable and infrequently specified. Finally, the small number of cases in some subgroups may not provide sufficient power to demonstrate a statistically significant difference in the rates of occlusion among age groups, different aneurysm sizes, prebifurcation-versus-bifurcation aneurysms, type of stent used, first treatment versus retreat- ment, and type of first treatment. However, although retrospective data are low in quality, our meta-analysis is the best available evidence to guide neurointerventionalists during flow-diversion treatment of MCA aneurysms.

\section{CONCLUSIONS}

Flow diversion for MCA aneurysms should only be considered as salvage therapy when traditional treatment methods are unfeasible, given the $10 \%$ rate of permanent neurologic morbidity. However, when performed in this select treatment group, high rates of aneurysm occlusion and protection against re-rupture can be achieved.

\section{ACKNOWLEDGMENTS}

We thank Professor Beth De Felici for the English revision.

Disclosures: Vincent Costalat-UNRELATED: Consultancy: Sequent Medical, Covidien, Stryker, Balt Extrusion; Payment for Lectures (including service on Speakers Bureaus): Covidien, Stryker, Sequent Medical; Payment for Development of Educational Presentations: Covidien, Stryker.

\section{REFERENCES}

1. Brinjikji W, Lanzino G, Cloft HJ, et al. Endovascular treatment of middle cerebral artery aneurysms: a systematic review and singlecenter series. Neurosurgery 2011;68:397-402; discussion 402 CrossRef Medline

2. Pierot L, Spelle L, Vitry F, et al; ATENA Investigators. Immediate clinical outcome of patients harboring unruptured intracranial aneurysms treated by endovascular approach: results of the ATENA study. Stroke 2008;39:2497-504 CrossRef Medline

3. Kallmes DF, Brinjikji W, Boccardi E, et al. Aneurysm Study of Pipeline in an Observational Registry (ASPIRe). Interv Neurol 2016;5: 89-99 CrossRef Medline

4. Rodriguez-Hernandez A, Sughrue ME, Akhavan S, et al. Current management of middle cerebral artery aneurysms: surgical results with a "clip first" policy. Neurosurgery 2013;72:415-27 CrossRef Medline

5. Bhogal P, AlMatter M, Bäzner H, et al. Flow diversion for the treatment of MCA bifurcation aneurysms: a single centre experience. Front Neurol 2017;8:20 CrossRef Medline

6. Bhogal P, Martinez R, Gansladt O, et al. Management of unruptured saccular aneurysms of the M1 segment with flow diversion: a single centre experience. Clin Neuroradiol 2016 Dec 11. [Epub ahead of print] CrossRef Medline

7. Briganti F, Napoli M, Leone G, et al. Treatment of intracranial aneurysms by flow diverter devices: long-term results from a single center. Eur J Radiol 2014;83:1683-90 CrossRef Medline

8. Caroff J, Neki H, Mihalea C, et al. Flow-diverter stents for the treatment of saccular middle cerebral artery bifurcation aneurysms. AJNR Am J Neuroradiol 2016;37:279-84 CrossRef Medline

9. Iosif C, Mounayer C, Yavuz K, et al. Middle cerebral artery bifurcation aneurysms treated by extrasaccular flow diverters: midterm angiographic evolution and clinical outcome. AJNR Am J Neuroradiol 2017;38:310-16 CrossRef Medline

10. Lin N, Lanzino G, Lopes DK, et al. Treatment of distal anterior circulation aneurysms with the Pipeline Embolization Device: a US multicenter experience. Neurosurgery 2016;79:14-22 CrossRef Medline

11. Pistocchi S, Blanc R, Bartolini B, et al. Flow diverters at and beyond the level of the circle of Willis for the treatment of intracranial aneurysms. Stroke 2012;43:1032-38 CrossRef Medline

12. Topcuoglu OM, Akgul E, Daglioglu E, et al. Flow diversion in middle cerebral artery aneurysms: is it really an all-purpose treatment? World Neurosurg 2016;87:317-27 CrossRef Medline

13. Yavuz K, Geyik S, Saatci I, et al. Endovascular treatment of middle 
cerebral artery aneurysms with flow modification with the use of the Pipeline embolization device. AJNR Am J Neuroradiol 2014;35: 529-35 CrossRef Medline

14. Zanaty M, Chalouhi N, Tjoumakaris SI, et al. Flow diversion for complex middle cerebral artery aneurysms. Neuroradiology 2014;56: 381-87 CrossRef Medline

15. Moher D, Liberati A, Tetzlaff J, et al. Preferred reporting items for systematic reviews and meta-analyses: the PRISMA statement. Int J Surg 2010;8:336-41 CrossRef Medline

16. Elsharkawy A, Lehecka M, Niemela M, et al. A new, more accurate classification of middle cerebral artery aneurysms: computed tomography angiographic study of 1,009 consecutive cases with 1,309 middle cerebral artery aneurysms. Neurosurgery 2013;73:94-102; discussion 102 CrossRef Medline

17. Wells G, Shea B, O'Connell D, et al. The Newcastle-Ottawa Scale (NOS) for assessing the quality of nonradomized studies in metaanalyses. Ottawa, Ontario: Ottawal Hospital Research Institute. 2011 http://www.evidencebasedpublichealth.de/download/Newcastle Ottowa_Scale_Pope_Bruce.pdf. Accessed May 2, 2017

18. DerSimonian R, Laird N. Meta-analysis in clinical trials. Control Clin Trials 1986;7:177-88 CrossRef Medline

19. Higgins JP, Thompson SG, Deeks JJ, et al. Measuring inconsistency in meta-analyses. BMJ 2003;327:557-60 CrossRef Medline

20. Gawlitza M, Januel AC, Tall P, et al. Flow diversion treatment of complex bifurcation aneurysms beyond the circle of Willis: a single-center series with special emphasis on covered cortical branches and perforating arteries. J Neurointerv Surg 2016;8:481-87 CrossRef Medline

21. Brinjikji W, Murad MH, Lanzino G, et al. Endovascular treatment of intracranial aneurysms with flow diverters: a meta-analysis. Stroke 2013;44:442-47 CrossRef Medline

22. Rouchaud A, Brinjikji W, Lanzino G, et al. Delayed hemorrhagic complications after flow diversion for intracranial aneurysms: a literature overview. Neuroradiology 2016;58:171-77 CrossRef Medline

23. Berge J, Biondi A, Machi P, et al. Flow-diverter Silk stent for the treatment of intracranial aneurysms: 1-year follow-up in a multicenter study. AJNR Am J Neuroradiol 2012;33:1150-55 CrossRef Medline

24. Kallmes DF, Hanel $\mathrm{R}$, Lopes $\mathrm{D}$, et al. International retrospective study of the Pipeline embolization device: a multicenter aneurysm treatment study. AJNR Am J Neuroradiol 2015;36:108-15 CrossRef Medline

25. Brinjikji W, Cloft $\mathrm{H}$, Cekirge S, et al. Lack of association between statin use and angiographic and clinical outcomes after Pipeline embolization for intracranial aneurysms. AJNR Am J Neuroradiol 2017;38:753-58 CrossRef Medline

26. Briganti F, Leone G, Marseglia M, et al. Endovascular treatment of cerebral aneurysms using flow-diverter devices: a systematic review. Neuroradiol J 2015;28:365-75 CrossRef Medline

27. Cruz JP, Marotta T, O'Kelly C, et al. Enhancing brain lesions after endovascular treatment of aneurysms. AJNR Am J Neuroradiol 2014; 35:1954-58 CrossRef Medline

28. Tan LA, Keigher KM, Munich SA, et al. Thromboembolic complica- tions with Pipeline Embolization Device placement: impact of procedure time, number of stents and pre-procedure $\mathrm{P} 2 \mathrm{Y} 12$ reaction unit (PRU) value. J Neurointerv Surg 2015;7:217-21 CrossRef Medline

29. Briganti F, Delehaye L, Leone G, et al. Flow diverter device for the treatment of small middle cerebral artery aneurysms. J Neurointerv Surg 2016;8:287-94 CrossRef Medline

30. Kim B, Kim K, Jeon P, et al. Thromboembolic complications in patients with clopidogrel resistance after coil embolization for unruptured intracranial aneurysms. AJNR Am J Neuroradiol 2014;35: 1786-92 CrossRef Medline

31. Berg P, Iosif C, Ponsonnard S, et al. Endothelialization of over- and undersized flow-diverter stents at covered vessel side branches: an in vivo and in silico study. J Biomech 2016;49:4-12 CrossRef Medline

32. Bartolini B, Blanc R, Pistocchi S, et al. "Y" and "X" stent-assisted coiling of complex and wide-neck intracranial bifurcation aneurysms. AJNR Am J Neuroradiol 2014;35:2153-58 CrossRef Medline

33. Hong Y, Wang YJ, Deng Z, et al. Stent-assisted coiling versus coiling in treatment of intracranial aneurysm: a systematic review and meta-analysis. PLoS One 2014;9:e82311 CrossRef Medline

34. Saleme S, Iosif C, Ponomarjova S, et al. Flow-diverting stents for intracranial bifurcation aneurysm treatment. Neurosurgery 2014; 75:623-31; quiz 631 CrossRef Medline

35. Brinjikji W, Lanzino G, Cloft HJ, et al. Patency of the posterior communicating artery after flow diversion treatment of internal carotid artery aneurysms. Clin Neurol Neurosurg 2014;120:84-88 CrossRef Medline

36. Daou B, Valle-Giler EP, Chalouhi N, et al. Patency of the posterior communicating artery following treatment with the Pipeline Embolization Device. J Neurosurg 2017;126:564-69 CrossRef Medline

37. Vedantam A, Rao VY, Shaltoni HM, et al. Incidence and clinical implications of carotid branch occlusion following treatment of internal carotid artery aneurysms with the Pipeline embolization device. Neurosurgery 2015;76:173-78; discussion 178 CrossRef Medline

38. Rangel-Castilla L, Munich SA, Jaleel N, et al. Patency of anterior circulation branch vessels after Pipeline embolization: longer-term results from 82 aneurysm cases. J Neurosurg 2017;126:1064-69 CrossRef Medline

39. Neki H, Caroff J, Jittapiromsak P, et al. Patency of the anterior choroidal artery covered with a flow-diverter stent. J Neurosurg 2015; 123:1540-45 CrossRef Medline

40. Rouchaud A, Leclerc O, Benayoun Y, et al. Visual outcomes with flow-diverter stents covering the ophthalmic artery for treatment of internal carotid artery aneurysms. AJNR Am J Neuroradiol 2015; 36:330-36 CrossRef Medline

41. Griessenauer CJ, Ogilvy CS, Foreman PM, et al. Pipeline Embolization Device for small paraophthalmic artery aneurysms with an emphasis on the anatomical relationship of ophthalmic artery origin and aneurysm. J Neurosurg 2016;125:1352-59 CrossRef Medline

42. Chalouhi N, Daou B, Kung D, et al. Fate of the ophthalmic artery after treatment with the Pipeline Embolization Device. Neurosurgery 2015;77:581-84; discussion 584 CrossRef Medline 